\title{
Er gletschere uberegnelige? - nyt tvarfagligt modelleringsprojekt
}

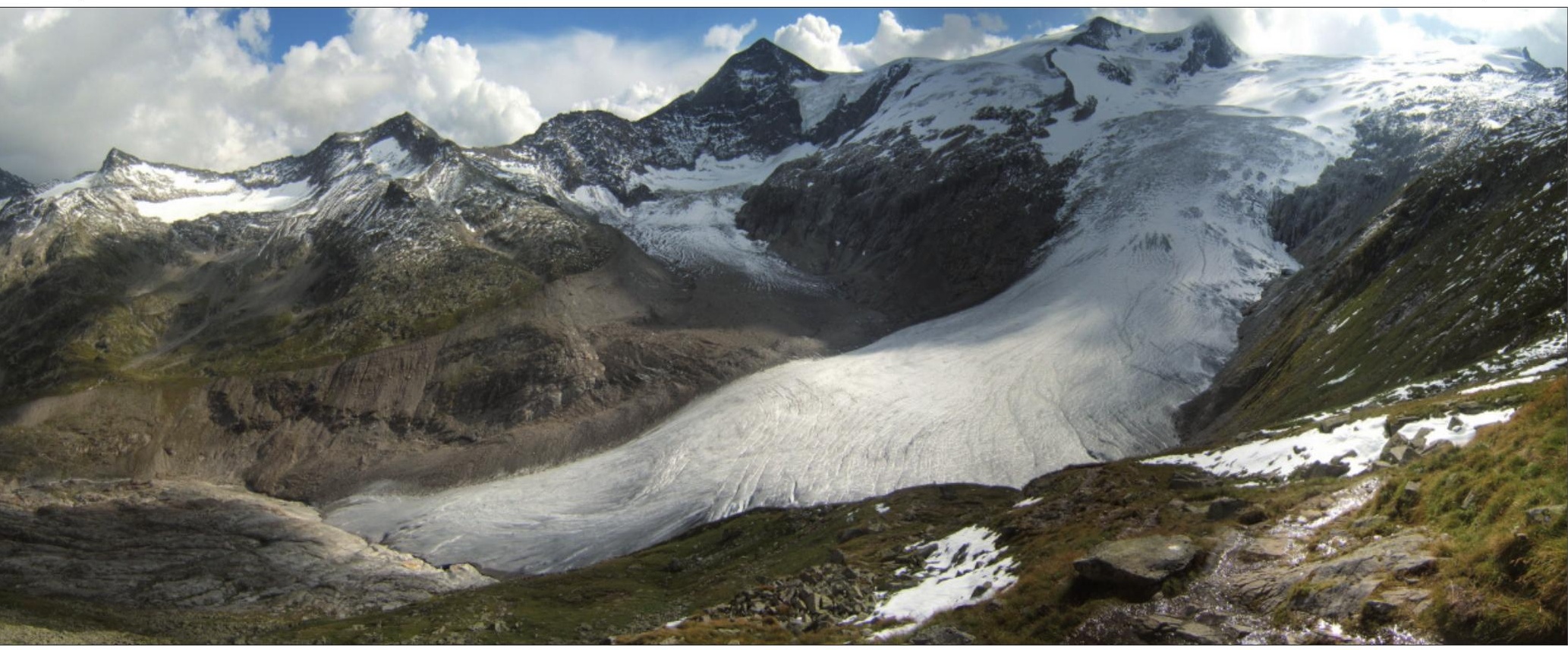

Gletscheren Schlatenkees naer Grossvenediger i Østrig. (Foto: Rafael Brix (SehLax), wikimedia commons)

Af lektor David Lundbek Egholm og professor Jan A. Piotrowski, Geologisk Institut, Aarhus Universitet

Gletschere er ansvarlige for dannelsen af nogle af de mest spektakulære landskaber på Jorden. Glaciale komponenter kan genkendes på stor skala i bjergkæder i form af bl.a. U-formede og hængende dale, cirkusdale og stejle tinder. I fladere landskaber som det danske, hvor isskjolde har været på spil, finder man bl.a. randmoræner, drumlinbakker, tunneldale og smeltevandsletter. Disse glaciale landskaber indeholder hver især information om processer og dynamiske forhold ved bunden af gletschere og isskjolde.

Ismasser, som pga. tyngdekraften langsomt deformeres og glider ned ad bjergskråninger og gennem dale, efterlader sig let genkendelige spor. Is og rindende vand har vidt forskellige måder at påvirke underlaget på, og derfor former gletschere og floder landskabet på forskellig vis. Norges dybe og stejle fjordsystemer er gode eksempler på glaciale landskaber, mens V-formede dale, hvis bundhøjde langsomt falder mod havniveau, er eksempler på fluviale landskaber.

En tur med GoogleEarth afslører mange eksempler på begge typer af landskaber; fx er Great Smokey Mountains i det sydøstlige USA (ca. 35 N., 83 V.) et klassisk fluvialt landskab. Området omkring Kebnekaise i det nordlige Sverige (ca. 68 N., 18,30’ Ø.) indeholder flotte cirkusdale, mens Grossvenediger i Østrig (ca. 47,06' N., 20,45' Ø.) har specielt flotte eksempler på eksisterende gletschersystemer.

Glaciale erosionsprocesser relativt ukendte Måske netop på grund af, at glaciale landskaber er let genkendelige, er det overraskende, hvor lidt geologer egentlig ved om glaciale erosionsprocesser. Man har kun få og usikre estimater af glaciale erosionsrater, og endnu mindre ved man om de rumlige erosionsmønstre. Vi har altså kendskab til slutprodukterne af den glaciale erosion $i$ form af de glaciale landskaber, men meget lidt kendskab til processerne, hvorved landskaberne dannes.

Dette skyldes naturligvis, at det er ganske kompliceret direkte at observere og kvantificere glaciale erosionsprocesser, som 1) finder sted under tykke ismasser, og dermed er åstedet ofte utilgængeligt for mennesker, og 2) foregår langsomt gennem lang tid $\left(10^{3}-10^{7}\right.$ år), men med hurtige og kortvarige variationer.

Det er altså svært at observere direkte, hvad der foregår under en gletscher. Derfor hersker der da også generel usikkerhed om, hvordan gletschere og isskjolde dynamisk vekselvirker med underlaget, hvilket ikke alene har betydning for erosionsprocesserne, men også for isens bevægelse og for gletscheres følsomhed over for klimaændringer. Men vi ved, at is eroderer bjergkæder, formodentlig hurtigere end floder kan gøre det. Endvidere ved vi, at ismasserne transporterer sediment frem til isranden, hvor det aflejres i bl.a. randmoræner eller transporteres videre af smeltevand. Præcis hvordan sedimenttransporten foregår, er kun dårligt belyst, og derfor er der god plads til underholdende uenighed, fx om mekanismer til dannelsen af randmoræner.

Et nyt projekt ved Geologisk Institut, Aarhus Universitet, omfatter nye computermodeller af gletschere og isskjolde. Modellerne er, i sammenligning med tidligere og eksisterende modeller, tværfaglige og indeholder ikke alene glaciologiske komponenter, men også hydrogeologiske, sedi- 


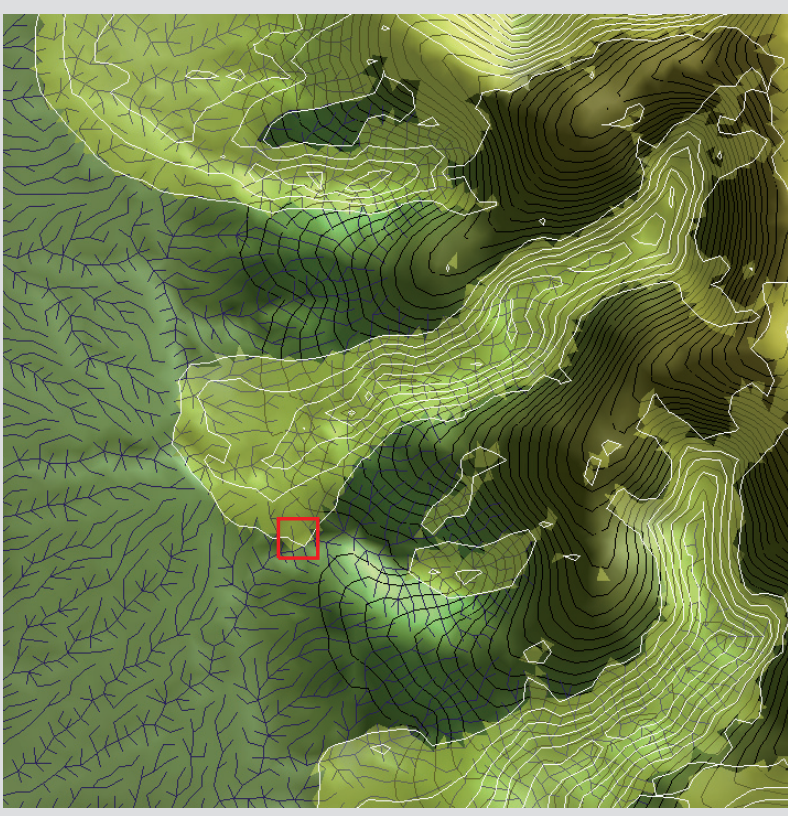

a)

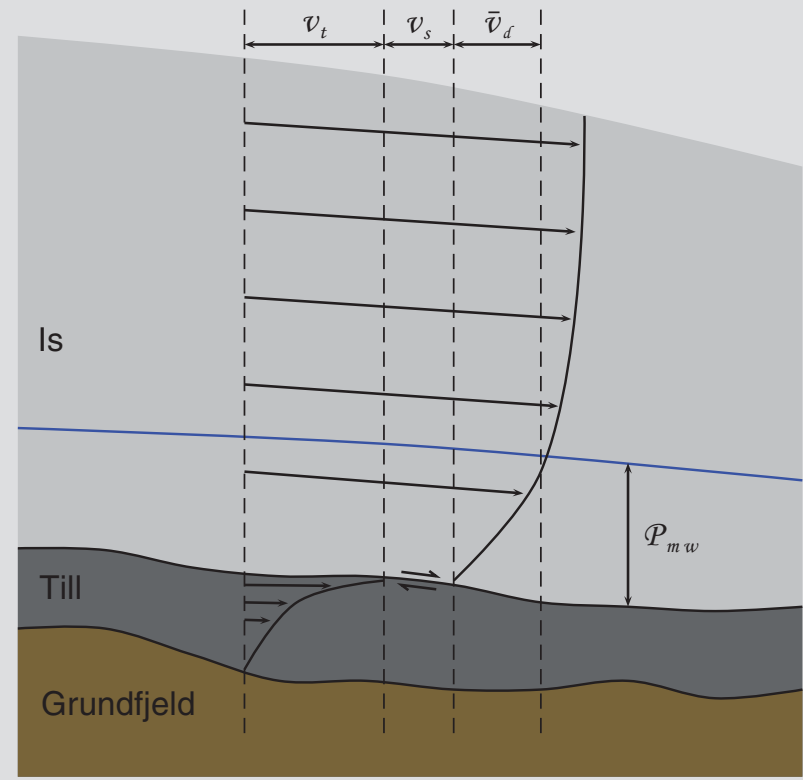

c)

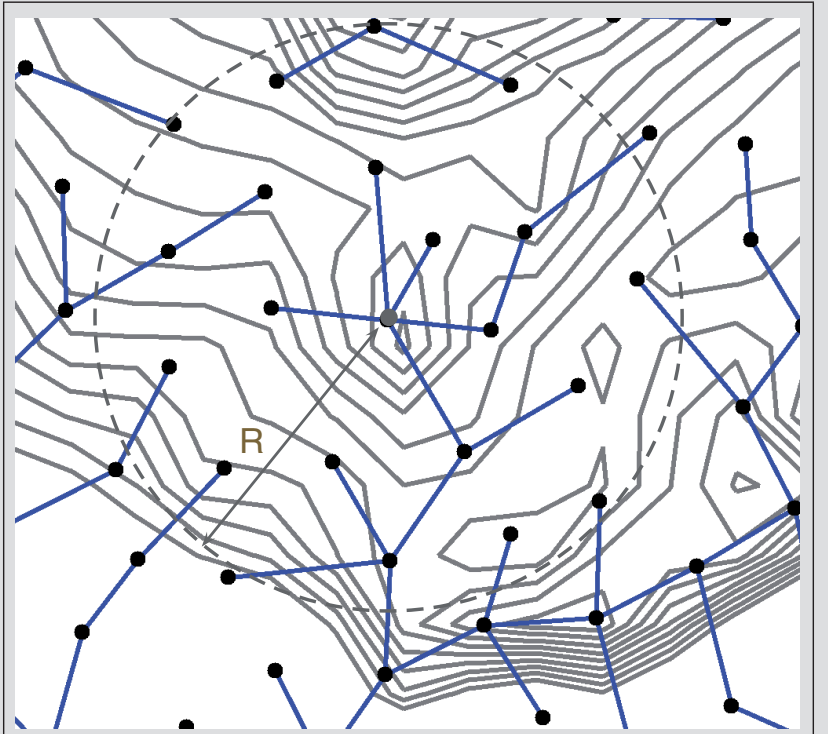

b)

Ligning for istykkelse $\left(h^{i}\right)$ :

$$
\frac{\partial h^{i}}{\partial t}=\nabla \cdot h^{i} v+\mathcal{M}
$$

Numerisk approksimation:

$$
\left.\frac{\partial h^{i}}{\partial t}\right|_{i}=\sum_{j}^{n(R)}\left(h_{j}^{i} v_{j}-h_{i}^{i} v_{i}\right) \cdot \nabla \Phi_{i j}
$$

Isdeformation:

$$
\bar{v}_{d}=\frac{2 \mathcal{A}_{d}}{n+2} \frac{\nabla \hbar}{\alpha} \tau_{b}^{n} h^{i^{2}}
$$

Isglidning:

$$
v_{s}=2 \mathscr{D}^{2} \mathcal{K} \frac{\left(\tau_{6}-\tau_{s}\right)^{a}}{\left(\mathscr{P}_{i}-\mathscr{P}_{m w}\right)^{6}}
$$

a) Modeludsnit set fra oven. Billedet viser et landskab (sorte konturer) med gletschere (gule med hvide konturer, der indikerer istykkelser) og fluviale drceningsmønstre (blå streger). Den røde kasse er forstørret i figur b) hvor modelnoderne er synlige. Den grå cirkel med radius $R$ indikerer området, hvor lokale "least squares-approksimationer" bestemmer istykkelsen i den grå node. Figur c) viser en modelskitse set fra siden med de horisontale hastigheder indtegnet. (Grafik: David L. Egholm)

mentologiske og geomorfologiske. Projekte formål er at skabe en tværgående modelbaseret platform, hvorpå forskelligartede observationer, som alle relaterer til gletschere og isskjolde, kan sammenholdes. Endvidere skal modelplatformen virke som et slags virtuelt laboratorium, hvor hypoteser kan testes ved at sammenligne modelforudsigelser med observationer.

\section{En ny beregningsmetode}

En ny beregningsteknik muliggør, at is-, vand-, og sediment-bevægelser kan simule- res samtidigt og $\mathrm{i}$ indbyrdes afhængighed. Til simulering af vandtransport, både subglacialt og fluvialt, benyttes et netværk af punkter. Noderne er irregulært fordelt på landskabets topografi, og vandet drives gennem netværket af trykforskelle, som opstår, enten når det isfri landskab skråner, eller når smeltevandstrykket under isen varierer. Netværket organiserer sig automatisk, så vandet flyder vinkelret på de største trykgradienter.

Bevægelsen af is og sedimenter simuleres vha. de samme punkter, men her benyttes lokale "least squares-approksimationer" til beregning af flydningshastighederne. Ved en lokal least squares-approksimation tilnærmes topografien et todimensionalt 2 . grads polynomium i et lille område omkring hvert punkt. Herefter beregnes gradienter i punkterne hurtigt ved analytisk differentiation. De lokale approksimationer muliggør modellering af meget ikke-lineær opførsel, som er specielt vigtigt for simulering af isbevægelser, idet gletschere kan udvise voldsomme hastighedsvariationer både i tid og rum. Derudover åbner de lokale approksimationer for at udnytte parallelberegninger 


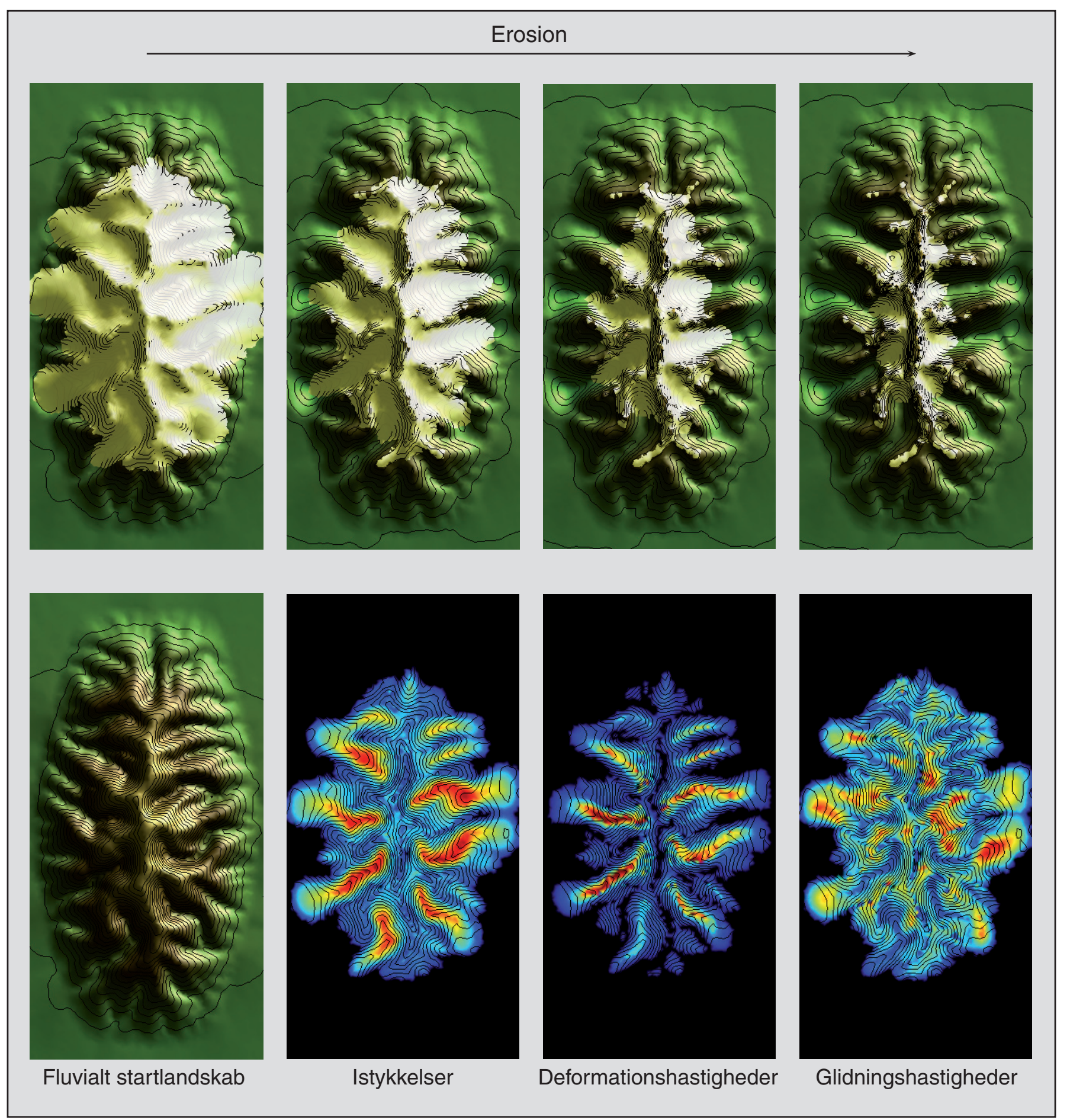

De øverste fire billeder viser, hvordan en computermodel forudsiger glacial erosion. Yderst til venstre ses det initielle landskab, lige efter isen har gjort sit indtog, mens de tre noeste billeder viser forskellige stadier af erosion. Isens volumen aftager med tiden, ikke pga. klimatiske variationer, men fordi landskabet eroderes og dermed aftager i højde. Isen ødeloggger altså gennem erosion sit eget eksistensgrundlag. Bemoerk hvordan dalene gøres bredere og stejlere. De fire nederste billeder viser henholdsvis det fluviale startlandskab samt konturer af istykkelser, deformationshastigheder og glidningshastigheder i modelstadiet svarende til billedet øverst til venstre. (Grafik: David L. Egholm)

på supercomputere, hvor mange processorer arbejder på samme model, men med hver sit lokale delområde.

Som udgangspunkt for modellerne opdeles isbevægelser i tre komponenter:

1) intern deformation,

2) basal glidning og

3) deformation af underlaget.

Den interne deformationen foregår over- alt $i$ isen og skyldes, at is mekanisk er en tyktflydende væske, som, når den udsættes for spændinger, konstant vil være i bevægelse. Deformationshastigheden er en funktion af dybden under isoverfladen, isoverfladens hældning samt temperaturen. Generelt integreres deformationshastighederne vertikalt $i$ modellerne.

\section{Basal glidning}

Den basale glidning og underlagets defor- mation er langt mere kompliceret at modellere, idet adskillige forhold tilsyneladende kan føre til destabilisering af de basale dynamiske forhold. Surgetype-gletschere er eksempler på en sådan destabiliseringproces, hvor de basale glidningshastigheder viser store tidslige variationer.

I den stabile passive fase er de basale glidningshastigheder små, men under den ustabile aktive fase vokser hastighederne pludseligt 10-100 gange, og gletscherfron- 
ten foretager et voldsomt fremstød (deraf begrebet "surging"). Man har ikke fundet en endegyldig forklaring på surge-fænomenet, men flere hypoteser er i spil. Bl.a. spekulerer man $i$, at variationer $i$ temperaturfordelingen ved gletscherens bund, forårsaget af varierende istykkelser, til tider fryser dele af getscheren fast til underlaget (koldbaseret), mens andre dele af gletscheren har en bundtemperatur lig isens smeltepunkt (varmbaseret).

Forekomsten af smeltevand kan medføre, at den varmbaserede is mekanisk afkobles underlaget og således skrider hurtigt, som når hjulene på en bil akvaplaner. Man antager endvidere, at raten, hvormed smeltevandet dannes, afhænger af isens bevægelse over underlaget, da friktionen mellem is og underlag skaber varme og dermed smeltevand. Der er altså tale om, at en selvforstærkende sammenhæng mellem smeltevand og isbevægelse måske forårsager surge-fænomenet.

\section{Isstrømme}

De basale glidningshastigheder kan ligeledes udvise store rumlige variationer. Ismasserne glider og deformerer generelt ned af bakke grundet tyngdekraften, og således flyder isen fra høje landområder mod de lavereliggende kystområder. Men bevægelsen er langt fra homogen. I de store isskjolde på Antarktis og i Grønland, findes de såkaldte ice streams, en slags isstrømme hvor isen bevæger sig meget hurtigt. På Antarktis er disse isstrømme op til $500 \mathrm{~km}$ lange og 20 til $100 \mathrm{~km}$ brede. Arealmæssigt dækker isstrømmene kun $10 \%$ af det antarktiske isskjold, men langt det meste is bevæger sig gennem disse på vejen fra Antarktis' indre til kysten, hvor det smelter eller søsættes som isbjerge.

Da isstrømmene således står for at dræne hovedparten af isen fra et isskjold, er deres forekomst og aktivitet helt afgørende for den samlede afsmeltning. I det glaciologisk videnskabelige miljø er der bred enighed om, at nøglen til at kortlægge de konsekvenser, klimatiske ændringer har for et isskjold, ligger i forståelsen af de basale glidningsfænomener.

Som i tilfældet med surgetype-gletsjere kan forekomsten af smeltevand måske forårsage dannelsen af isstrømme, men man mistænker derudover underlagets beskaffenhed for at spille en vigtig rolle. Isen vil generelt bevæge sig hurtigere, hvis underlaget består af mekanisk svage sedimenter, som ikke kan understøtte isens spændinger, end hvis underlaget består af stærke bjergarter, der ikke let lader sig flytte.

Hvis man ønsker at simulere bl.a. surgefænomener og isstrømme, må man altså regne med at skulle forholde sig ikke blot til bevægelser af is, men også af vand og sediment. Derfor indeholder computermodellerne følgende 7 komponenter, som hver især kan aktiveres efter behov:

\section{Klimavariationsmodel}

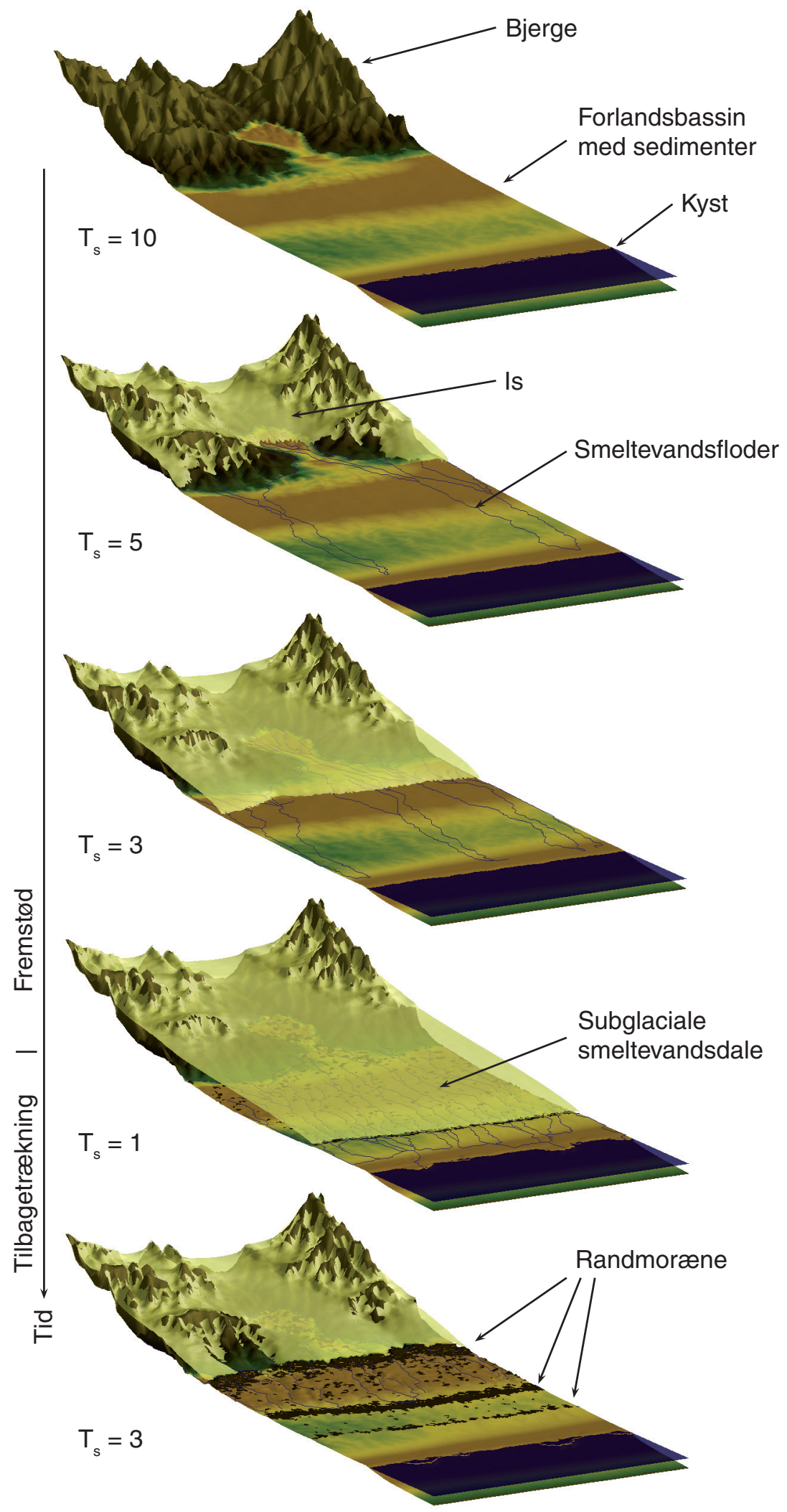

Model med klimatiske variationer. I de øverste fire billeder aftager temperaturen ved havniveau, og et isskjold vokser frem fra bjergene og daekker det flade forland. Det nederste billede viser modellen, efter at temperaturen igen er vokset. Temperaturstigningen sker i tre ryk, hvilket forårsager dannelsen af tre store randmorcener, hvor isfronten i perioder er relativt stationcer. (Grafik: David L. Egholm) 
1. Thermomekanisk isbevægelse,

2. Glacial erosion, transport og aflejring

3. Fluvial erosion, transport og aflejring

4. Skrænterosion

5. Grundvandsstrømning

6. Isostatisk eller tektonisk landhævning

7. Marin aflejring

Modelkomponenternes antal giver os nye muligheder for at belyse glaciale fænomener, som opstår i krydsfeltet mellem forskelligartede geologiske processer. Men antallet af modelkomponenter stiller også betydelige krav til projektdeltagernes tværfaglighed, idet modellerne samtidigt berører information af glaciologisk, geomorfologisk, hydrogeologisk og sedimentologisk karakter. På den anden side, giver projektet netop, gennem modelkomponenterne, mulighed for at danne en tværfaglig platform, hvor samarbejde mellem forskellige forskere er umiddelbart fordelagtigt, og hvor videnskabelige synergieffekter derfor kan opstå.

Det er vigtigt at påpege, at modellerne ikke i selv bidrager med ny viden, men kun når de sammenholdes med observationer. I den forbindelse opererer projektet specielt med en "bottom up" indgangsvinkel, hvor det undersøges, hvilke modelkomponenter der som minimum er nødvendige for at genskabe realistiske glaciale landskaber. Den observationelle del af modelleringsprojektet udføres i samarbejde bl.a. med geografer fra University of Sheffield i England, som en del af SAGA, Sheffield - Aarhus Geoscience Alliance. Sheffield-gruppen indsamler og behandler satellitbilleder af glaciale landskaber og er eksperter i ud fra billederne at udpege mønstre og systematisk at kvantificere den glaciale erosion.

\section{Klimatiske variationer}

Modellernes sammenkobling af fluviale og glaciale processer muliggør endvidere beregninger af sediment-produktion og transport i klimatiske overgangsperioder, hvor de dominerende erosionsprocesser $\mathrm{fx}$ går fra at være fluviale til at være glaciale. I sådanne perioder anslår man, at erosion og sedimentproduktion er særligt hurtig, idet landskabets former ændrer karakter. Fx omformes de fluviale V-formede dale til glaciale U-formede dale samtidig med, at aflejringsmøntre omdannes så fx tidligere depocentre udsættes for hurtig erosion, og sediment omlejres. Sådanne klimatiske skift, som den kvartære periode tilsyneladende var fuld af, anses derfor for at være potentielle kilder til hurtig erosion, sedimentproduktion samt isostatisk hævning.

En pludselig øget sedimentproduktion, som erkendes igennem eksistensen af tykke aflejringer fra en bestemt periode, formodes ofte at have baggrund i tektonik eller havniveaufald, idet det antages, at erosionshastigheden af landmasser over havniveau er relativt konstant, og at den øgede produktion skyldes, at landmasserne over havniveau er vokset $i$ areal.

Men noget tyder på, at klimatiske variationer, som $\mathrm{fx}$ medfører at glaciale erosionsprocesser kommer og går, kan forårsage lignende signaler, og det er interessant at undersøge om computermodellerne kan udpege testparametre, som kan hjælpe os til at skelne mellem tektonik og klimavariationer som mekanismer til øget sedimentproduktion. I den forbindelse er det særligt nyttigt at sammenligne modelforudsigelser med geofysiske målinger af bjergarters erosionshistorie. Sidstnævnte kan bl.a. opnås gennem fissionssporsanalyser, som beskrevet i artiklen "Norges fjelde" af Søren Bom Nielsen på side 22-24 i dette nummer. 